\title{
How do macro-level structural determinants affect inequalities in mental health? - a systematic review of the literature
}

\author{
A. McAllister ${ }^{1 *}$ D, S. Fritzell ${ }^{1,2}$, M. Almroth ${ }^{1}$, L. Harber-Aschan', S. Larsson ${ }^{1}$ and B. Burström
}

\begin{abstract}
Background: In Europe and elsewhere there is rising concern about inequality in health and increased prevalence of mental ill-health. Structural determinants such as welfare state arrangements may impact on levels of mental health and social inequalities. This systematic review aims to assess the current evidence on whether structural determinants are associated with inequalities in mental health outcomes.

Methods: We conducted a systematic review of quantitative studies published between 1996 and 2017 based on search results from the following databases Medline, Embase, Psychlnfo, Web of Science, Sociological Abstracts and Eric. Studies were included if they focused on inequalities (measured by socio-economic position and gender), structural determinants (i.e. public policies affecting the whole population) and showed a change or comparison in mental health status in one (or more) of the Organisation for Economic Cooperation and Development (OECD) countries. All studies were assessed for inclusion and study quality by two independent reviewers. Data were extracted and synthesised using narrative analysis.

Results: Twenty-one articles (17 studies) met the inclusion criteria. Studies were heterogeneous with regards to methodology, mental health outcomes and policy settings. More comprehensive and gender inclusive welfare states (e.g. Nordic welfare states) had better mental health outcomes, especially for women, and less gender-related inequality. Nordic welfare regimes may also decrease inequalities between lone and couple mothers. A strong welfare state does not buffer against socio-economic inequalities in mental health outcomes. Austerity measures tended to worsen mental health and increase inequalities. Area-based initiatives and educational policy are understudied.

Conclusion: Although the literature on structural determinants and inequalities in mental health is limited, our review shows some evidence supporting the causal effects of structural determinants on mental health inequalities. The lack of evidence should not be interpreted as lack of effect. Future studies should apply innovative methods to overcome the inherent methodological challenges in this area, as structural determinants potentially affect both levels of mental health and social inequalities.
\end{abstract}

Keywords: Mental health, Structural determinants, Systematic review, Inequalities, Gender, Socio-economic, Equity

\footnotetext{
* Correspondence: ashley.mcallister@ki.se

'Department of Public Health Sciences, Karolinska Institutet, Stockholm,

Sweden

Full list of author information is available at the end of the article
}

(C) The Author(s). 2018 Open Access This article is distributed under the terms of the Creative Commons Attribution 4.0 International License (http://creativecommons.org/licenses/by/4.0/), which permits unrestricted use, distribution, and reproduction in any medium, provided you give appropriate credit to the original author(s) and the source, provide a link to the Creative Commons license, and indicate if changes were made. The Creative Commons Public Domain Dedication waiver (http://creativecommons.org/publicdomain/zero/1.0/) applies to the data made available in this article, unless otherwise stated. 


\section{Introduction}

The burden and prevalence of mental ill-health and mental illnesses are increasing [1]. Research shows that there are many explanations for this such as better awareness and diagnosis, environmental factors, structural factors and changes in public policy [2]. In this review, we focus on the structural, defining structural determinants as public policies affecting the whole population [3], we propose six main domains of welfare states, family policy, employment policy, income support and social insurance policy, area-based initiatives and education policy (see further explanation below). The Swedish Government commissioned The Public Health Agency of Sweden to increase the knowledge on mental health inequalities and their underlying determinants, this study is part of this larger project. Against this background, the main focus of the review was on studies of structural determinants and policies in Western welfare states. We define mental health broadly including positive mental health, mental ill-health and diagnoses of mental illnesses. Overall, we aim to investigate whether structural determinants are associated with mental health outcomes and if these determinants differentially impact on mental health outcomes by socio-economic status (SES) and gender.

The following provides a further explanation of inequalities in mental health and structural determinants of mental health.

\section{What are inequalities in mental health?}

The burden of mental illness is not equally distributed in the population. Epidemiological evidence consistently demonstrates an inverse association between SES and psychiatric morbidity, such that more disadvantaged groups are affected by mental illness to a greater extent [4]. Also, demographic factors such as gender and ethnicity (although not in themselves modifiable) may further modify the risk of mental disorder, depending in turn on how wealth, power and resources are distributed by gender and ethnicity (see for example [5, 6]). This further suggests that distributions of mental illness are systematically shaped by social, economic as well as physical environments throughout the life-course [7], putting more disadvantaged population sub-groups at greater risk for mental illnesses through exposure to unfavourable social and economic circumstances.

\section{How are structural determinants related to mental health?}

We propose that structural determinants affect the distribution of resources and have the potential to influence mental health inequalities. Previous research shows that welfare state arrangements, social and economic policy may influence the distribution of health between social groups [3, 8-12]. We used this literature to deconstruct structural determinants into six public policy domains: welfare states, family policy, employment policy, income support and social insurance policy, area-based initiatives and education policy (see Table 1). Borrell, et al. [3] suggest that such policy domains are drivers of the social structure and power relations that ultimately generate social inequalities in health. We suggest that these policy domains may mitigate or reduce the risk of poor mental health that provides the conditions for everyday life and influence the opportunities available to people across the life course. We also acknowledge the importance of healthcare policies in shaping access to services, and that these are likely to contribute to mental health inequalities. However, we do not asses these in this review as we conceptualise these as downstream factors influencing the treatment of mental illnesses, as opposed to broader structural determinants of mental illness.

We included all welfare typologies in our review. We propose, that regardless of the typology, examining welfare regimes provides insight into the values and norms that influence structural determinants. To illustrate, we use Korpi's [13] family model regime typology. The dual-earner/carer models (e.g. Denmark, Sweden, Norway, Finland) are characterised by providing universalistic public policies to encourage labour force participation and gender equality. In contrast, the market-oriented model (e.g. Australia, the United Kingdom and the United States) provides limited social protection mostly towards those considered 'deserving' through means-tested benefits. In

Table 1 Policy domains and examples

\begin{tabular}{|c|c|}
\hline Policy domain & Explanation and examples \\
\hline 1. Welfare state & Typologies of welfare states, based on family policy, social policy or other dimensions. \\
\hline 2. Family policy & Levels of benefits, changes in eligibility, coverage, public daycare, custody laws, parental leave. \\
\hline 3. Employment policy & $\begin{array}{l}\text { Minimum wage, flexibility, precariousness, tax-credits/subsidies, active labour market policies, } \\
\text { employment protection legislation, anti-discrimination law, strength of unions. }\end{array}$ \\
\hline 4. Income support and social insurance & Levels of benefits (including unemployment), changes in eligibility, coverage. \\
\hline 5. Area-based initiatives & $\begin{array}{l}\text { Affordable housing, availability, subsidies, regulations on eviction, quality of housing, } \\
\text { neighbourhood renewal. }\end{array}$ \\
\hline 6. Education (at all levels) & Affordability, access, developmental support. \\
\hline
\end{tabular}


this welfare regime, the market, rather than public policy determines gender roles. In traditional family models, (e.g. Belgium, the Netherlands, Spain), policies are organised around the family with men often viewed as the 'breadwinner'. Unpaid labour is seen as a responsibility of the family rather than the state which leads to low support for female labour force participation.

While social determinants of mental illness have long been recognised [7, 14], only recently have they received more attention, especially in the wake of the recent economic crisis [15]. However, most empirical research focuses on proximal, "down-stream" determinants and few focus on broader, "upstream", what we define as structural determinants and how these might affect social distributions of mental illness. To the best of our knowledge, no systematic review of the literature exists on structural determinants and their impact on mental health outcomes. We specifically sought to answer the following:

1. Which structural determinants (i.e. public policies) are associated with inequalities in mental health outcomes?

2. In what context have these policies been implemented?

3. What social differentials (across socio-economic groups and between men and women) exist regarding mental health outcomes?

\section{Methods}

This review was structured in accordance with the Preferred Reporting Items for Systematic Reviews and Meta-Analyses (PRISMA) guidelines [16], with additional focus on equity using the PRISMA-E 2012 [17].

\section{Information sources and search strategy}

We searched for eligible articles in the following databases: Medline (Ovid), Embase (Embase.com), PsycINFO (Ovid), Web of Science, Sociological Abstracts (ProQuest) and ERIC (ProQuest). The Karolinska Institutet Library completed the initial search on 16 March 2017 and an updated search on 7 November 2017.

We also reviewed publications of recognised experts in this area as well as other relevant studies and projects such as Evaluating the Impact of Structural Policies on Health Inequalities (SOPHIE) [18]. Two reviewers also screened the bibliographies of all relevant reviews. See Additional file 1 for a detailed search strategy. Ethical approval was not required as results are based on previously published papers.

\section{Eligibility criteria}

Articles were considered eligible if they were (1) Original, peer-reviewed, written in English and published between 1996 and 2017. (2) Quantitative studies showing a change or comparison in mental health status (i.e. mental disorder diagnosis, positive (self-rated) mental health, suicide rate) using a validated mental health measure, and (3) Examined one of the policy domains (Table 1) in at least one of the Organisation for Economic Cooperation and Development (OECD) countries. See Additional file 2 for more information about the inclusion and exclusion criteria used in the selection process.

\section{Study selection}

We employed two levels of screening to identify relevant studies. All screening tools were pilot tested before each level of screening. In the following section, we briefly describe each level:

\section{Level 1 - Title and abstract screening}

Most articles were excluded at this level because the title and abstract did not focus on mental health and/or one of the policy domains. This was primarily conducted by SL. Another reviewer (AM) independently applied the criteria for inclusion and exclusion to $14 \%$ of the title and abstracts (350 references). Any disagreements between SL and AM were resolved after discussions.

\section{Level 2 - Full-text screening}

The selection criteria were clarified and rewritten for the Level 2 - Full-text screening. Four reviewers participated in Level 2 screening. All articles were reviewed by at least two reviewers. The review team discussed articles where there were disagreements on final decisions $(30 \%)$. If the team could not agree, then the article was reviewed by a third member of the review team. AM was responsible for making all final decisions.

\section{Study quality assessment and risk of bias}

All included articles were assessed using the "Health Evidence Bulletin, Wales: Questions to assist with the critical appraisal of an observational study" (hereto referred to as HEB - Wales Tool) [19]. The HEB - Wales Tool is one of the few quality assessment tools that is designed to fairly assess different study designs. The tool has been endorsed by Sanderson, et al. [20] for its ability to be used to assess cohort, case-control and cross-sectional study designs; transparency regarding development; applicability for future use; and use of a checklist system which we used to develop a rating scale. We adapted the tool so that questions were most relevant to our study aims (see Additional file 3).

While the HEB - Wales Tool was designed as a checklist rather than a scoring tool, we agreed on a scoring system (a priori) where the study was given a score of two if the criteria for the item was met. If it was unclear then a score of one was given, and if it clearly did not meet the criteria then a score of zero was given. Each study was 
given a total score out of 30 possible points. If a study had a score of more than 23 points (the authors met at least $80 \%$ of the items), then it was classified as high quality. Medium quality studies had a cut-off score between 18 to 23 points and low-quality studies scored 17 points or less (the authors only met $60 \%$ of the items). All articles were quality appraised by two reviewers. The final score is an average of the two reviewers' scores (see Additional file 4 for a summary of the scores).

We assessed the risk of bias in individual studies using Part B of the HEB - Wales Tool entitled "Do I trust it?" In this section, we assessed whether the study design and study population was appropriate, confounding and bias were considered in the study, and there was a long enough follow-up time. Most of the risk of bias was assessed at the design rather than outcome level.

\section{Data extraction strategy}

A data extraction template was created and piloted by SF and AM. Using this template, we extracted data from all articles that were marked as 'included' in Level 2 screening. Four reviewers completed this phase, with two reviewers assigned to each article to extract data. AM then compared the results and completed a summary table. Any discrepancies were resolved through discussion between the two reviewers.

\section{Data items}

Table 2 summarises the data items extracted from each article.

\section{Data synthesis}

We used narrative analysis to synthesise the data. Categorising the policy domains and focusing on the two specific types of inequalities (gender and SES), were deliberate strategies intended to make the data synthesis clearer. Furthermore, other data items extracted such as study design, population, and setting were intentional measures to assist with comparing heterogeneity in the studies. The implementation of the HEB-Wales Tool also made it possible to systematically compare the quality of the studies.

Table 2 Data items from each article

\begin{tabular}{ll}
\hline $\begin{array}{l}\text { Article } \\
\text { information }\end{array}$ & Author, year, aim, setting (i.e. country) \\
\hline $\begin{array}{l}\text { Characteristics } \\
\text { of study }\end{array}$ & $\begin{array}{l}\text { Study population, sample size, method of } \\
\text { data collection and year(s) covered }\end{array}$ \\
Exposures & $\begin{array}{l}\text { Policy domains (1-6), policy sub-area, name of } \\
\text { policy }\end{array}$ \\
$\begin{array}{l}\text { Outcome } \\
\text { measures }\end{array}$ & $\begin{array}{l}\text { Mental health aspect, mental health (validated) } \\
\text { Inequality }\end{array}$ \\
measure & $\begin{array}{l}\text { Assessed socio-economic status or gender inequality } \\
\text { (increase/decrease/neutral) }\end{array}$ \\
\hline
\end{tabular}

\section{Results}

\section{Study selection}

The search strategy and other sources produced 3394 papers which were assessed for inclusion in the review. Data were extracted from 21 papers that met our eligibility criteria. Figure 1 shows a PRISMA flow diagram of the selection process.

\section{Study characteristics}

The 21 selected articles were representative of 17 different studies or data sources. The majority investigated European countries, including 10 articles involving Sweden. Five articles, however, included data from Australia, Canada, the USA and Japan. Twelve of the studies compared two or more countries, while the remaining nine focused on a single country. One study focused on adolescents and the remaining 20 involved a working age population ${ }^{1}$.

Thirteen articles used cross-sectional methods and 10 used longitudinal methods, two of which used a natural policy experiment design.

The articles measured constructs of positive mental health, mental ill-health and diagnoses of mental illnesses. Positive mental health constructs were represented in 11 articles and included mental health functioning, mental well-being and social-emotional development. Mental distress, poor mental health, depression, suicide rates, psychiatric diagnosis and anti-depressant prescription represent the negative aspects of mental health and diagnoses of mental illnesses measured in 10 of the studies. Several validated mental health measures were used including the World Health Organization Well-Being Index (WHO-5), the Global Health Questionnaire (GHQ-12), the Short Form Health Survey (SF36 and SF12), the Centre for Epidemiological Studies Depression Scale (CES-D8), Mental Health Inventory (MHI-5), Ages and Stages Questionnaire (ASQ-SE), Health Behaviour in School Age Children (HBSC), Self-Reported Health in the Quarterly Labour Force Survey, suicide statistics and register data for psychiatric diagnoses.

Five articles focused only on gender inequalities in mental health, and 12 articles measured only SES inequalities, with four investigating both types of inequalities. Table 3 summarizes the results from the 21 included articles.

As results showed that the type of welfare regime strongly influenced the direction of some policy domains, the dimensions of employment policies, family policies and income support and social insurance policies, were added as sub-domains to the welfare state domain. The following section outlines the results by each policy domain or sub-domain.

\section{Welfare states}

Nine articles focused on the policy domain of overall welfare states [21-29], meaning that comparisons were made 


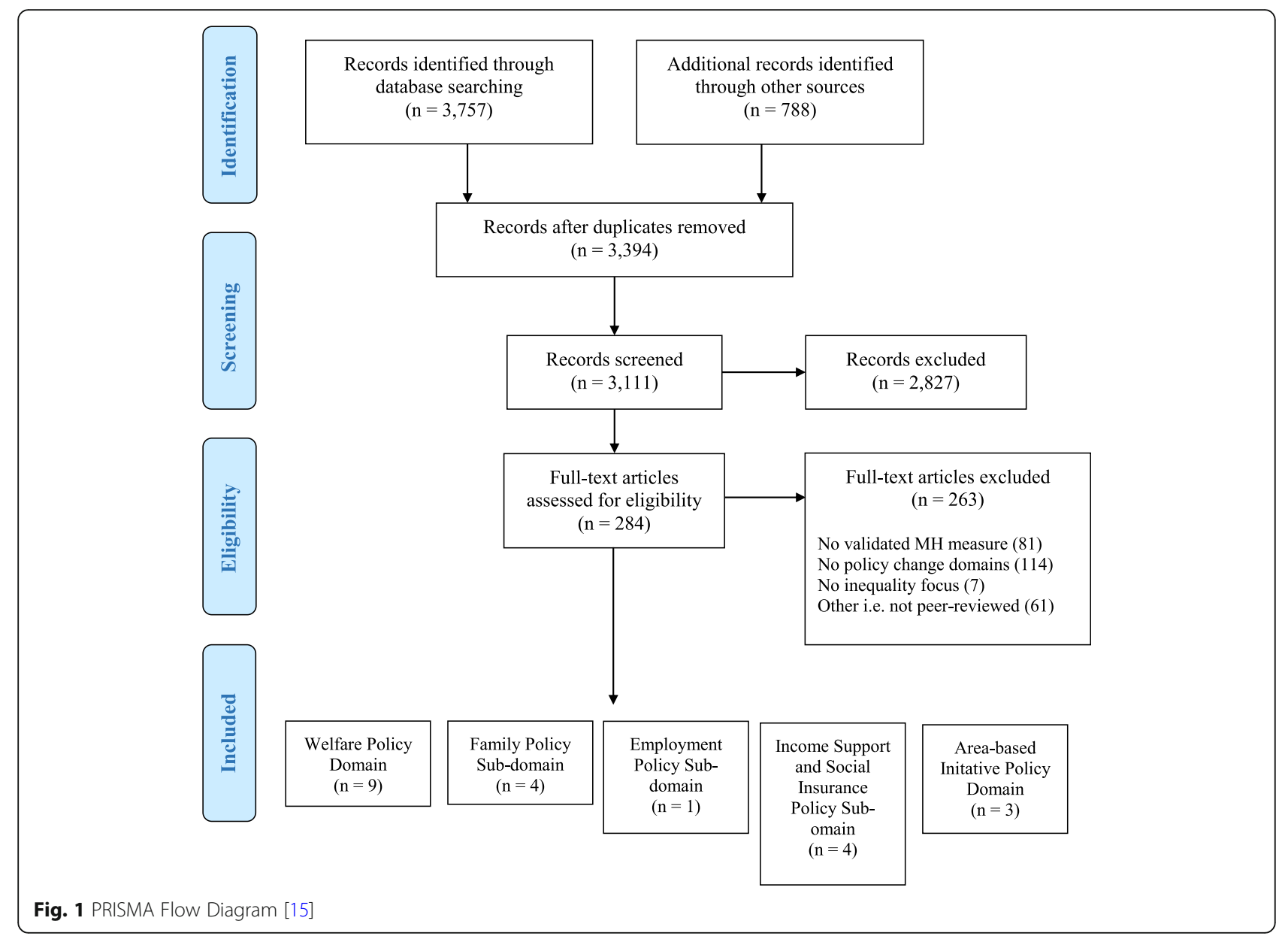

by categorising European countries into welfare regime types, such as the Nordic dual earner/carer model, family oriented, and market-oriented models. Four of the nine articles addressed gender inequalities, three addressed SES inequalities and two addressed gender and SES. Two articles, (Sekine, et al. [26] and Sekine, et al. [27]) were based on the same study, but the former focused on SES inequalities while the latter focused on gender inequalities. Only one study focused on social expenditures [29] and the other eight focused on employment or work characteristics within different welfare regimes.

A dual-earner model where both partners contribute to wage earning and care responsibilities (typically in the Nordic countries) seems to be associated with better mental health outcomes for women while the market-oriented model (e.g. the UK) was associated with worse mental health outcomes for women [21-23, 27, 28]. There also appears to be less of a gap between men and women when it comes to mental health functioning in the dual-earner model [23]. Furthermore, greater investment in social spending and family focused welfare models were associated with better mental health outcomes for women [29].

\section{Family policy}

Four articles focused on the policy sub-domain of family [30-33]. One of these focused-on gender inequality while the other three focused on SES inequality. Findings from Huang, et al. [32] and Rathmann, et al. [33] had opposing conclusions in that Huang, et al. [32] found that cash benefits reduced mental health inequalities between children of lone and couple mothers, and Rathmann, et al. [33] concluded that an increase in family benefits actually led to a greater gap in SES inequality in mental health outcomes. The limited evidence generally suggests that investment in family benefits leads to overall better mental health outcomes but may not reduce the gap in inequalities in mental health outcomes.

\section{Employment policy}

Only one article focused on the policy sub-domain of employment and addressed gender and SES inequality [34]. As such, we cannot conclude about inequalities in mental health outcomes related to this domain. However, given the quality of the study design and the large sample size, we should consider that in this case, austerity measures 


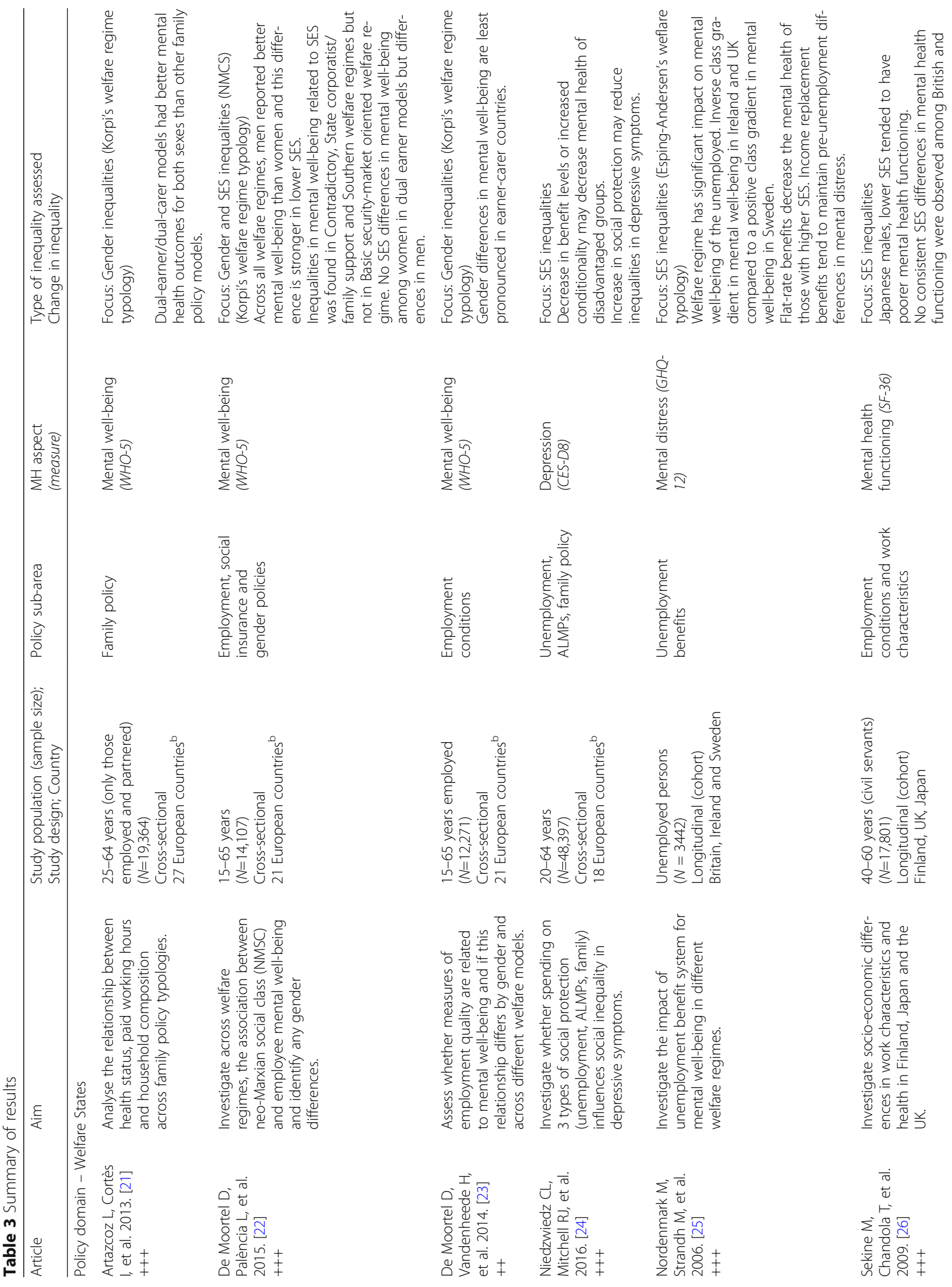




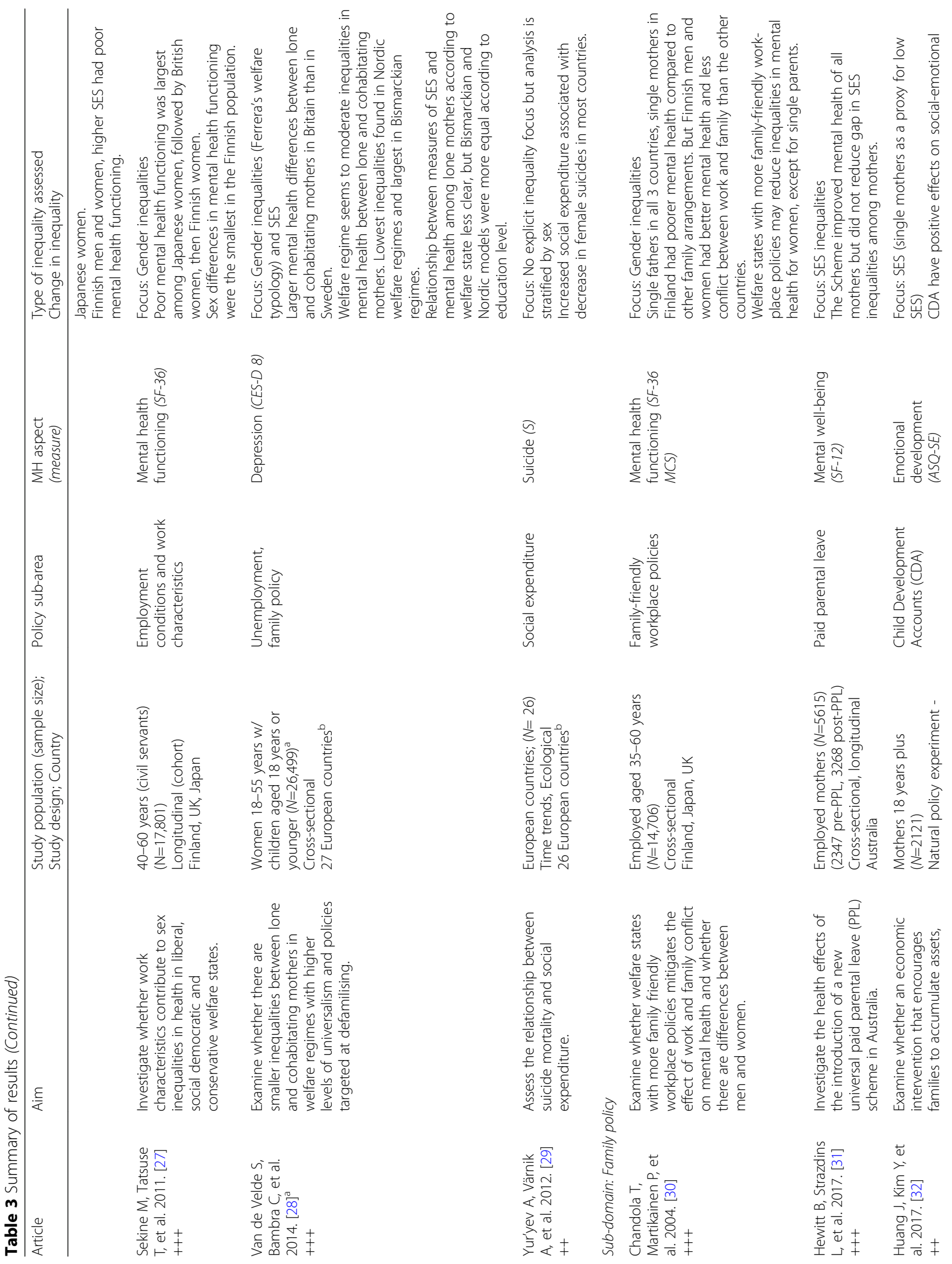




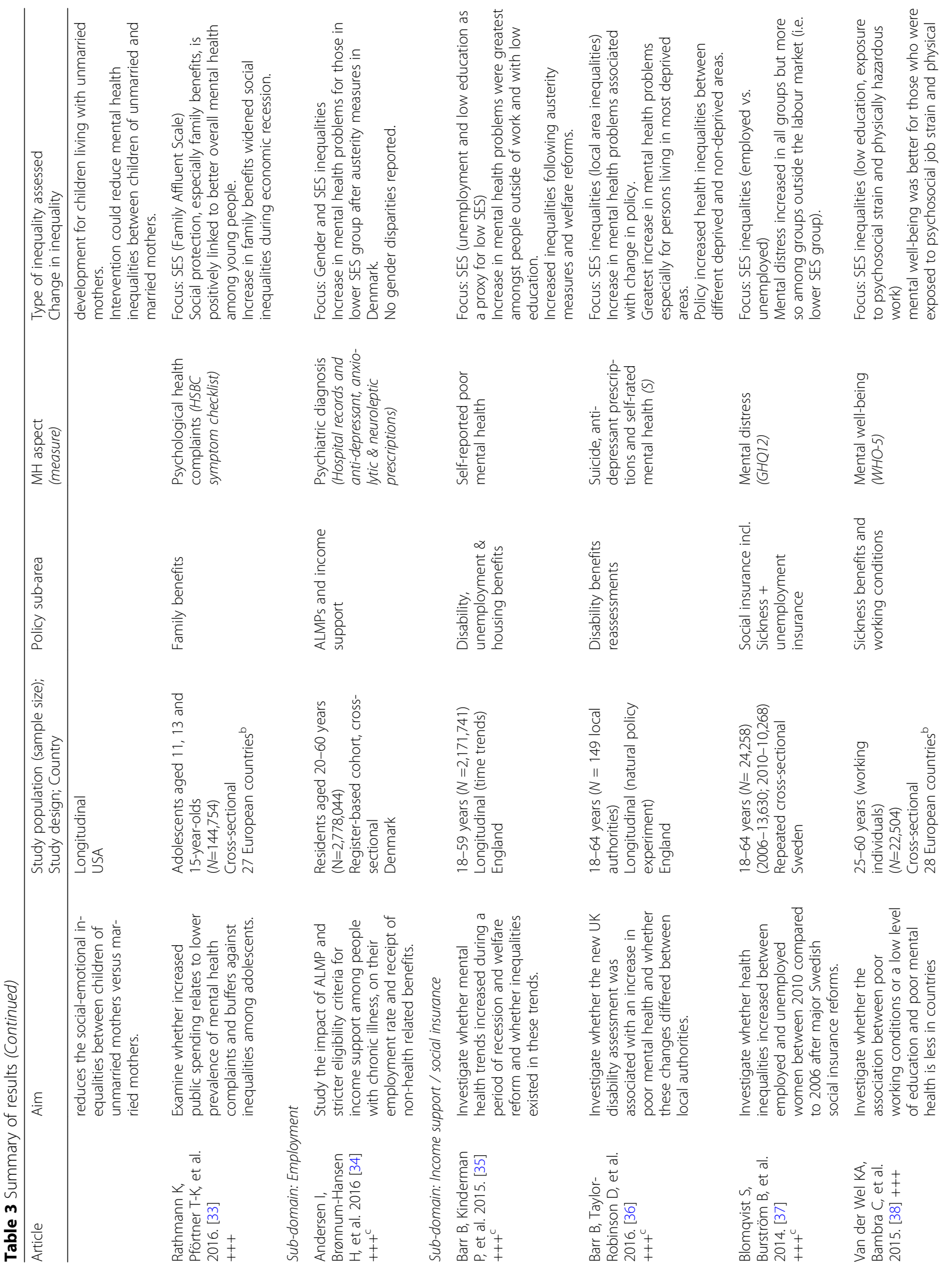




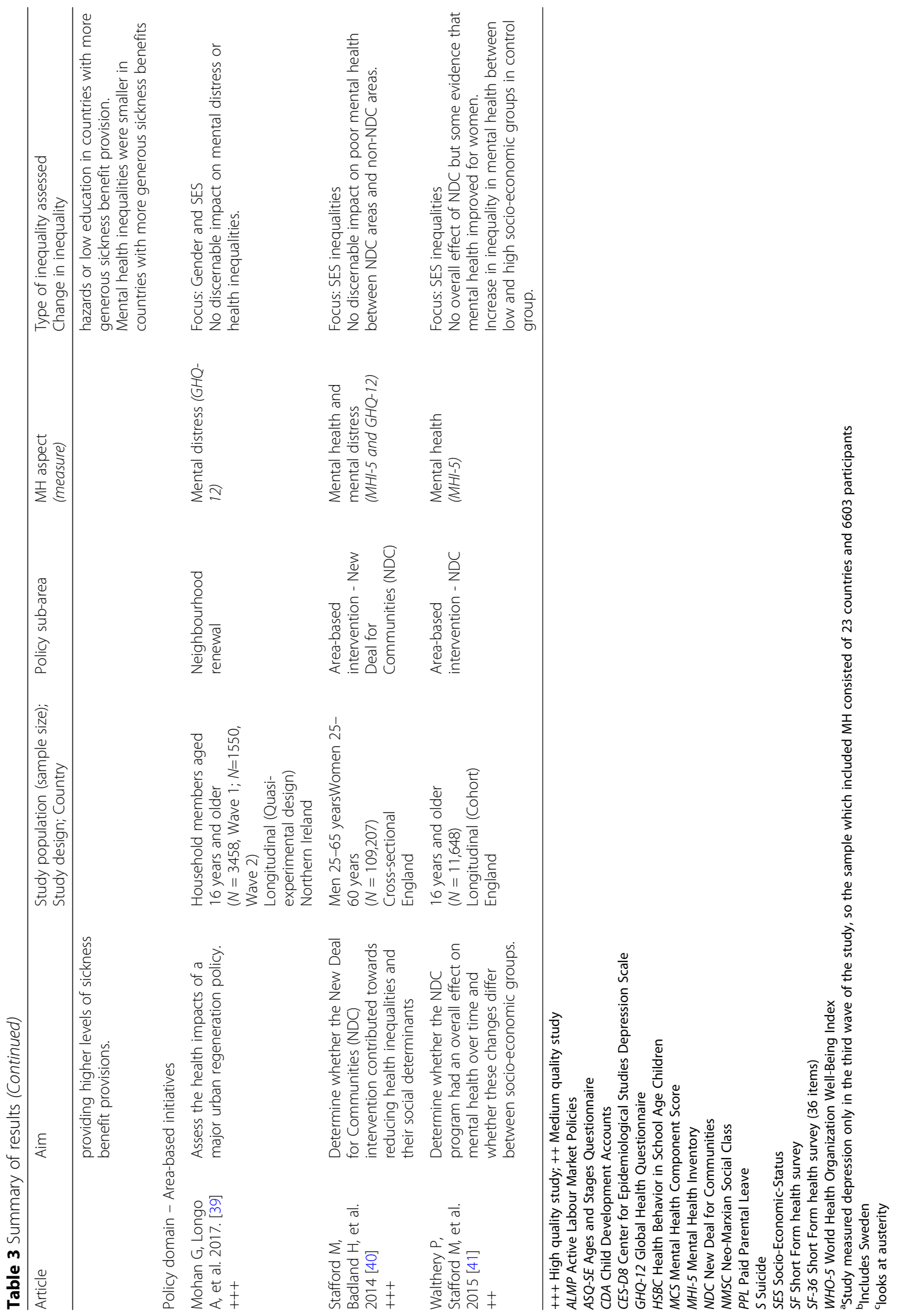


contributed to worse mental health outcomes among lower SES groups [34].

\section{Income support and social insurance}

Four studies focused on the policy sub-domain of income support, all of which analysed SES inequalities rather than gender inequalities [35-38]. Three of these articles focused on austerity measures and found that mental health inequalities increased, and particularly vulnerable groups experienced greater mental health problems. Van der Wel, et al. [38] found that mental health inequalities were smaller in countries with more generous sickness benefits. It is unclear if these effects are a direct result of the policies or if they work through other mechanisms. For example, Barr, et al. [36] suggest that austerity measures may have contributed to increased suicide rates and other mental health problems while Blomqvist, et al. [37] conclude that inequalities in mental health among women could be due to stricter eligibility criteria and decrease in benefit levels but there is no definitive evidence that policy change (i.e. tightening eligibility criteria and reduced benefit levels) leads to mental distress. The limited evidence shows that more generous welfare benefits are associated with better mental health outcomes and austerity measures are associated with poorer mental health outcomes including increased suicide rates. Additionally, austerity measures seem to contribute to widening the social inequalities gap.

\section{Area-based initiatives}

Three articles focused on the policy domain of area-based initiatives, or interventions in a specific geographical location [39-41]. Two studies focused on the New Deal for Communities initiative in England [40, 41] with both focusing on SES inequality. Mohan, et al. [39] studied a different area-based initiative and focused on gender and SES inequality. Limited results regarding area-based initiatives show that these interventions can prevent or reduce the gap in social inequalities of mental health, or at least prevent the widening of this gap in the targeted areas, and that neighbourhood renewals in more disadvantaged areas provide some improvement to women's mental well-being.

\section{Education}

We did not find any articles focused on the policy domain of education which met our criteria. We therefore cannot draw any conclusions related to educational policy and mental health inequalities.

\section{Discussion}

We synthesised the literature examining the impact of structural determinants on mental health inequalities, specifically focusing on economic and social policies underpinning the welfare state, and prevailing societal norms (see Table 4). Of the 21 research articles identified, most were observational studies, and only two studies used a natural policy experiment study design. Of the policy domains examined, welfare states were the most comprehensively researched. We should note that most included studies focusing on welfare states used a regime approach (e.g. Korpi's [13]) but as Bergqvist, et al. [42] argue there are other ways to examine welfare states such as through an institutional or expenditure approach. Other approaches may provide alternative perspectives on our research question.

This review indicates that more comprehensive and gender inclusive welfare states lead to better mental health outcomes especially for women, but there is little evidence that this reduces socio-economic inequalities. We discuss these issues separately below.

\section{Gender inequalities and mental health}

Evidence from the welfare state domain indicated that dual-earner models (typically found in the Nordic countries) were associated with better mental health outcomes and less prominent mental health inequalities by gender, compared to other welfare regimes especially basic-security/market welfare states [21, 23, 26-28]. These findings align with findings of Borrell, et al. [3] that in dual-earner models, public policies support women's employment while imposing more equitable sharing of domestic work leading to better health outcomes.

Three studies examined the intersection between gender and relationship status [28, 30,32], highlighting a socially and economically vulnerable group of women; lone mothers. Van de Velde, et al. [28] found that, in general, lone mothers' mental health seems to be worse than cohabitating mothers, aligning with other studies (see for example [43-46]. Included studies looked at welfare state arrangements and tested specific measures to lessen financial strain. Van de Velde, et al. [28] conclude that welfare regimes may moderate inequalities in mental health between lone and cohabitating mothers, finding smaller inequalities in Sweden (i.e. Nordic welfare regime) than Britain (i.e. Market-oriented welfare regime). Huang, et al. [32] suggests that cash benefits to lone mothers are one way to reduce the gap in mental health between children of lone and cohabitating mothers. However, Bergqvist, et al. [42] notes that reducing inequalities takes a combination of generous family benefits and supporting women in the labour market. On the other hand, Whitehead, et al. [44] found that the pressure for lone mothers to work in Sweden could contribute to worse health outcomes. Many studies show that family policies facilitate the work-family balance and decrease financial strain, both factors are associated with better health among lone mothers (see for example [44-46], however, many of these 
Table 4 Summary of changes in inequality by policy domain

\begin{tabular}{ll}
\hline Policy domain & Summary of changes in inequalities \\
\hline Welfare States & $\begin{array}{l}\text { The evidence indicates that the Nordic model was associated with fewer mental health problems and fewer } \\
\text { gender inequalities compared to other welfare regimes especially basic-security/market welfare states. } \\
\text { The evidence indicates that welfare regimes with more inclusive family policies may reduce inequalities in } \\
\text { mental health outcomes for women. } \\
\text { The evidence indicates increases in mental health problems for those in lower SES after welfare reforms } \\
\text { (austerity measures). } \\
\text { The evidence indicates that restrictions on income support may have negative effects (see employment). } \\
\text { Income Support } \\
\text { More generous welfare benefits are associated with fewer SES inequalities in mental health. } \\
\text { Education }\end{array} \quad \begin{array}{l}\text { The evidence indicates that neighbourhood renewals in more disadvantaged areas provide some improvement } \\
\text { to women's mental well-being. }\end{array}$ \\
\hline
\end{tabular}

studies mostly focus on mothers' general health, rather than mental health outcomes.

While outside the scope of our article, some included studies [23, 26, 27] emphasised the role that job quality plays in gender differences. For example, De Moortel, et al. [23] purposes that differential exposure to bad quality employment (e.g. non-permanent contracts, low wage, lack of union representation) is partly explained by welfare regimes.

\section{Socio-economic inequalities and mental health}

While the Nordic countries seem to produce better mental health outcomes for women, our results do not support that this approach reduces socio-economic inequalities in mental health outcomes. Rather, our results support Mackenbach's [47] conclusions that strong welfare states such as in Sweden do not buffer against socio-economic inequalities in health.

We found that the evidence on welfare states and socio-economic inequalities was inconsistent. On the one hand, Niedzwiedz, et al. [24] suggests that higher spending on active labour market programmes reduced inequalities, specifically by improving mental health outcomes among those with the lowest education. However, Rathmann, et al. [33] found that higher spending on social protection, especially during the recent recession, is not enough to reduce the socio-economic inequalities in the mental health of adolescents. Rather, the authors suggest that a combination of social spending and programs directly targeting adolescents could be more effective [33]. Hewitt, et al. [31] also found that increased spending on paid parental leave, improved overall maternal mental health but did not decrease the gap between mothers with low SES and high SES.

Contrasting these studies, Nordenmark, et al. [25] note that socio-economic inequalities could be wider in Sweden than the UK because of a 'levelling down' process that happens with those in higher SES in the UK. The authors explain that persons with higher SES experience greater economic strain receiving flat-rate benefits (i.e. the UK) as their drop in income is larger, compared to countries with income replacement (i.e. Sweden), leading to poorer mental health outcomes on flat-rate benefits than persons with lower SES [25].

\section{Austerity measures associated with poor mental health outcomes}

Four of the included studies [34-37] showed an association between poor mental health outcomes and austerity measures - reducing government spending, e.g. by cutting programs and reducing benefit levels. A growing body of literature on the direct and indirect health effects of austerity measures support our findings (see for example [15, 48]). More generous public policies like those in Nordic welfare states are associated with better overall mental health outcomes, even if they do not reduce socio-economic inequalities.

\section{Why so little on education policy?}

We propose that the absence of studies focused on education policy is in part because most school policy and school intervention research focus on academic outcomes rather than mental health outcomes. Academic outcomes are more accessible to researchers given that children are already assessed based on their school performances. Academic achievement is closely related to mental health, and the two are associated throughout the life course [49], however, more research is warranted to disentangle some of these mechanisms. Furthermore, school is often seen as a neutral environment that is supposed to 'level the playing field' to some extent. The focus of inequality is often based on students' background characteristics rather than what actually happens at school, or how these factors interact [50]. Other studies examine much older policy changes and do not explicitly focus on mental health outcomes (see for example [51]). Further research on school-level determinants of mental health outcomes and investigation of school systems which have undergone changes in educational policy may help elucidate some of these questions. 


\section{Limitations}

Readers should interpret results from this review with caution, given the heterogeneity of the literature with regards to methodology, mental health outcomes and policy settings. Other methodological limitations included inconsistencies in choice of comparison groups, and datasets often lacking sufficient information to comprehensively adjust for confounding factors, both at the individual and area-level.

The generalizability of our study is also somewhat limited by the definitions used. Our mental health definition included all aspects of mental health meaning that our analysis did not capture the nuanced differences, for example, between different mental illnesses or psychiatric comorbidity as opposed to mental well-being [52]. Our definition of structural determinants was also broad encompassing many policies, making policy conclusions challenging. Whitehead, et al. [44] suggest that a better approach is to focus on specific groups in the population and particular policies. We deliberately took a broad approach to get an overview, given that no systematic review has examined structural determinants and inequalities of mental health before.

Health inequalities is a growing field of research. Given the potential importance of structural determinants of mental illness, it is surprising that we did not find more research articles assessing this research question. There are clearly methodological challenges in designing studies in this area. We must also note that important variations in study context mean that other factors, such as economic trends, migration trends, and the political climate may have played a role. Furthermore, it is important to acknowledge the time lag from policy implementation to observing any associated effects on mental health [53].

\section{Implications}

To the best of our knowledge, this is the first review to examine structural determinants in inequalities in mental health. Additionally, our study is one of the few that focuses specifically on mental health outcomes rather than inequalities focused on self-rated health outcomes. Our study provides an overview of what limited evidence is available in this field and identifies areas of future research and policy directions.

\section{Research}

In this review, we identified important gaps in the literature for future research. Area-based initiatives and educational policy for example are understudied. Studies should specifically research inequalities, if we are to increase knowledge in this area. Methodologically, we need more natural policy experiments and more studies utilising historical cohort data to examine effects of structural determinants over a longer time frame. Studies drawing on the life-course approach would also strengthen this area of research, given that the risk of mental illnesses may start as early as in childhood and may accumulate over time. Finally, we must acknowledge that the health care system may be a possible mediator. However, given that most mental health policy research focuses on health care access we intentionally excluded the health care domain from this review to focus on other important policy domains. Future research should integrate the health policy domain.

Research comparing welfare states is important, but we must also compare within welfare states (e.g. [43]) and follow change over time. For example, although the Nordic countries share an overall ethos of equality and a strong focus on gender equality, there are differences between policy designs in each country [46]. As such, more case study research on the different policy designs of Nordic countries are needed before we can conclude that all Nordic countries promote better mental health outcomes for women.

\section{Policy}

The findings from this review bear some relevance to policy. For instance, our results indicate that austerity measures are associated with poor mental health outcomes and possibly increased suicides $[29,36]$. Our findings should be a cautionary tale for governments wanting to shrink welfare states.

Our review also indicates that improving mental health outcomes may present policy-makers with a trade-off between reducing socio-economic inequalities or improving overall mental health outcomes. We need more innovative policy solutions that reduce the risk of this trade-off.

\section{Conclusion}

In Europe and elsewhere, rising concern about inequality in health and increased prevalence of mental ill-health, means that ignoring the structural policies that may contribute to inequalities in mental health is no longer an option. This review provides knowledge to policy-makers and researchers when considering reforming policies to reduce inequalities in mental health outcomes. While, this review shows limited evidence supporting the causal effects of structural determinants on socio-economic inequalities in mental health, we found some evidence that policy may affect gender inequalities. The lack of evidence should not be interpreted as lack of effect. To strengthen the evidence base within the structural determinants of mental health inequalities research field and inform policies to reduce inequalities in mental health, future studies should seek to apply innovative methods to overcome the inherent methodological challenges in this area. 


\section{Endnotes}

${ }^{1}$ The study by Huang et al. 2017 included mothers as participants but measured mental health on the child level. Thus the exposure was on the adult level and the outcome was on the child level.

\section{Additional files}

Additional file 1: Detailed Search Strategy. (DOCX $37 \mathrm{~kb}$ )

Additional file 2: Inclusion/Exclusion Criteria for Review. (DOCX 24 kb)

Additional file 3: Quality Appraisal Tool. (DOCX 23 kb)

Additional file 4: Quality Assessment Scores. (XLSX 19 kb)

\section{Abbreviations}

ALMP: Active Labour Market Policies; ASQ-SE: Ages and Stages Questionnaire; CDA: Child Development Accounts; CES-D8: Centre for Epidemiological Studies Depression Scale; GHQ-12: Global Health Questionnaire; HBSC: Health Behaviour in School-Age Children; HEB-Wales Tool: Health Evidence Bulletin, Wales; MCS: Mental Health Component Score; MH: Mental Health; MHI5: Mental Health Inventory; MWB : Mental Well-Being; NDC : New Deal for Communities; NMSC: Neo-Marxian Social Class; OECD: Organization for Economic Co-operation and Development; PPL: Paid Parental Leave; PRISMA: Preferred Reporting Items for Systematic Reviews and MetaAnalyses; SES: Socio-Economic Status; SF: Short Form Health Survey; SF36: Short Form Health Survey (36 items); SOPHIE: Evaluating the Impact of Structural Policies on Health Inequalities; WHO: World Health Organization

\section{Acknowledgements}

We would like to thank Nadja Trygg for comments on previous drafts of the study.

\section{Funding}

This work was funded by the Public Health Agency of Sweden as part of governmental initiative to increase the knowledge on mental health inequalities and their underlying determinants.

\section{Availability of data and materials}

Not applicable. However, to demonstrate transparency, we have provided supplementary files documenting the search process.

\section{Authors' contributions}

AM and SF designed the study. SL conducted initial screening and AM quality checked. AM, SF, SL and MA conducted level two screening, quality assessment and data extraction. AM, SF, MA, LHA and BB contributed to presentation of analysis. AM wrote the first draft of the manuscript with contribution from MA, LHA, SF and BB. All authors read and approved the final manuscript.

\section{Ethics approval and consent to participate}

Ethical approval was not required because results are based on previously published papers.

\section{Consent for publication}

Not applicable.

\section{Competing interests}

The authors declare that they have no competing interests.

\section{Publisher's Note}

Springer Nature remains neutral with regard to jurisdictional claims in published maps and institutional affiliations.

\section{Author details}

${ }^{1}$ Department of Public Health Sciences, Karolinska Institutet, Stockholm, Sweden. ${ }^{2}$ The Public Health Agency of Sweden, Stockholm, Sweden.
Received: 6 June 2018 Accepted: 22 October 2018

Published online: 06 December 2018

\section{References}

1. World Health Organisation. Mental Disorders. 2017. www.who.int/newsroom/fact-sheets/detail/mental-disorders Accessed 21 May 2018.

2. Henderson C, Thornicroft G, Glover G. Inequalities in mental health. Br J Psychiatry. 1998;173:105-9.

3. Borrell C, Palència L, Muntaner C, Urquía M, Malmusi D, O'Campo P. Influence of macrosocial policies on women's health and gender inequalities in health. Epidemiol Rev. 2013;36:31-48.

4. Lorant V, Deliège $D$, Eaton W, Robert A, Philippot P, Ansseau M. Socioeconomic inequalities in depression: a meta-analysis. Am J Epidemiol. 2003;157:98-112.

5. Steel Z, Marnane C, Iranpour C, Chey T, Jackson JW, Patel V, et al. The global prevalence of common mental disorders: a systematic review and metaanalysis 1980-2013. Int J Epidemiol. 2014;43:476-93.

6. Kessler RC. Epidemiology of women and depression. J Affect Disord. 2003; 74:5-13.

7. Allen J, Balfour R, Bell R, Marmot M. Social determinants of mental health. Int Rev Psychiatry. 2014;26:392-407.

8. Beckfield J, Krieger N. Epi + demos + cracy: linking political systems and priorities to the magnitude of health inequities--evidence, gaps, and a research agenda. Epidemiol Rev. 2009;31:152-77.

9. Lundberg O, Yngwe MÅ, Stjärne MK, Elstad Jl, Ferrarini T, Kangas O, et al. The role of welfare state principles and generosity in social policy programmes for public health: an international comparative study. Lancet. 2008;372:1633-40

10. Navarro V, Muntaner C, Borrell C, Benach J, Quiroga Á, Rodríguez-Sanz M, et al. Politics and health outcomes. Lancet. 2006;368:1033-7.

11. Navarro V, Shi L. The political context of social inequalities and health. Soc Sci Med. 2001;52:481-91.

12. Diderichsen F, Andersen I, Manuel C, Working Group of the Danish Review on Social Determinants of Health, Andersen A-MN, Bach E, et al. Health inequality-determinants and policies. Scand J of Public Health. 2012;40 Suppl 8:12-105.

13. Korpi W. Faces of inequality: gender, class, and patterns of inequalities in different types of welfare states. Soc Polit. 2000;7(2):127-91.

14. WHO: Social determinants of mental health. 2014. www.who.int/mental_ health/publications/gulbenkian_paper_social_determinants_of_mental_ health/en/. Accessed 28 Nov 2017.

15. Reeves A, McKee M, Stuckler D. Economic suicides in the great recession in Europe and North America. BJPsych. 2014;205:246-7.

16. Moher D, Liberati A, Tetzlaff J, Altman DG, The PRISMA Group Preferred Reporting Items for Systematic Reviews and Meta-Analyses. The PRISMA Statement. PLoS Med. 2009;6:e1000097. https://doi.org/10.1371/journal. pmed. 1000097

17. Welch V, Petticrew M, Petkovic J, Moher D, Waters E, White H, et al. Extending the PRISMA statement to equity-focused systematic reviews (PRISMA-E 2012): explanation and elaboration. Int J Equity Health. 2015;14:92

18. Agència de Salut Pública de Barcelona. Evaluating the Impact of Structura Policies on Health Inequalities. 2012. www.sophie-project.eu/ Accessed 31 May 2018.

19. Health Evidence Bulletin - Wales. Questions to assist with the critical appraisal of an observational study eg cohort, case-control, cross-sectional. Wales: HEB Wales; 2004.

20. Sanderson S, Tatt ID, Higgins J. Tools for assessing quality and susceptibility to bias in observational studies in epidemiology: a systematic review and annotated bibliography. Int J Epidemiol. 2007:36:666-76.

21. Artazcoz L, Cortès I, Puig-Barrachina V, Benavides FG, Escribà-Agüir V, Borrell C. Combining employment and family in Europe: the role of family policies in health. Eur J Pub Health. 2013;24:649-55.

22. De Moortel D, Palència L, Artazcoz L, Borrell C, Vanroelen C. Neo-Marxian social class inequalities in the mental well-being of employed men and women: the role of European welfare regimes. Soc Sci Med. 2015;128:188-200.

23. De Moortel D, Vandenheede H, Vanroelen C. Contemporary employment arrangements and mental well-being in men and women across Europe: a cross-sectional study. Int J Equity Health. 2014;13:90.

24. Niedzwiedz CL, Mitchell RJ, Shortt NK, Pearce JR. Social protection spending and inequalities in depressive symptoms across Europe. Soc Psychiatry Psychiatr Epidemiol. 2016;51:1005-14. 
25. Nordenmark M, Strandh M, Layte R. The impact of unemployment benefit system on the mental well-being of the unemployed in Sweden, Ireland and Great Britain. Eur Soc. 2006:8:83-110.

26. Sekine M, Chandola T, Martikainen P, Marmot M, Kagamimori S. Socioeconomic inequalities in physical and mental functioning of British, Finnish, and Japanese civil servants: role of job demand, control, and work hours. Soc Sci Med. 2009;69:1417-25.

27. Sekine M, Tatsuse T, Kagamimori S, Chandola T, Cable N, Marmot M, et al. Sex inequalities in physical and mental functioning of British, Finnish, and Japanese civil servants: role of job demand, control and work hours. Soc Sci Med. 2011;73:595-603.

28. Van de Velde S, Bambra C, Van der Bracht K, Eikemo TA, Bracke P. Keeping it in the family: the self-rated health of lone mothers in different European welfare regimes. Sociol Health IIIn. 2014;36:1220-42.

29. Yur'yev A, Värnik A, Värnik P, Sisask M, Leppik L. Role of social welfare in European suicide prevention. Int J Soc Welf. 2012;21:26-33.

30. Chandola T, Martikainen P, Bartley M, Lahelma E, Marmot M, Michikazu S, et al. Does conflict between home and work explain the effect of multiple roles on mental health? A comparative study of Finland, Japan, and the UK. Int J Epidemiol. 2004;33:884-93.

31. Hewitt B, Strazdins L, Martin B. The benefits of paid maternity leave for mothers' post-partum health and wellbeing: evidence from an Australian evaluation. Soc Sci Med. 2017;182:97-105.

32. Huang J, Kim Y, Sherraden M, Clancy M. Unmarried mothers and children's social-emotional development: the role of child development accounts. J Child Fam Stud. 2017;26:234-47.

33. Rathmann K, Pförtner T-K, Osorio AM, Hurrelmann K, Elgar FJ, Bosakova L, et al. Adolescents' psychological health during the economic recession: does public spending buffer health inequalities among young people? BMC Public Health. 2016;16:860.

34. Andersen I, Brønnum-Hansen H, Kriegbaum M, Hougaard CØ, Hansen FK, Diderichsen F. Increasing illness among people out of labor market-a Danish register-based study. Soc Sci Med. 2016;156:21-8.

35. Barr B, Kinderman $P$, Whitehead $M$. Trends in mental health inequalities in England during a period of recession, austerity and welfare reform 2004 to 2013. Soc Sci Med. 2015;147:324-31.

36. Barr B, Taylor-Robinson D, Stuckler D, Loopstra R, Reeves A, Whitehead M. 'First, do no harm': are disability assessments associated with adverse trends in mental health? A longitudinal ecological study. J Epidemiol Community Health. 2016;70:339-45.

37. Blomqvist S, Burström B, Backhans MC. Increasing health inequalities between women in and out of work-the impact of recession or policy change? A repeated cross-sectional study in Stockholm county, 2006 and 2010. Int J Equity Health. 2014;13:51.

38. Van der Wel KA, Bambra C, Dragano N, Eikemo TA, Lunau T. Risk and resilience: health inequalities, working conditions and sickness benefit arrangements: an analysis of the 2010 European working conditions survey. Sociol Health IIIn. 2015;37:1157-72.

39. Stafford M, Badland H, Nazroo J, Halliday E, Walthery P, Povall S, et al. Evaluating the health inequalities impact of area-based initiatives across the socioeconomic spectrum: a controlled intervention study of the new Deal for communities, 2002-2008. J Epidemiol Community Health. 2014;68:979-86.

40. Walthery P, Stafford M, Nazroo J, Whitehead M, Dibben C, Halliday E, et al. Health trajectories in regeneration areas in England: the impact of the new Deal for communities intervention. J Epidemiol Community Health. 2015:69:762-8.

41. Mohan G, Longo A, Kee F. Evaluation of the health impact of an urban regeneration policy: neighbourhood renewal in Northern Ireland. J Epidemiol Community Health. 2017;71:919-27.

42. Bergqvist K, Yngwe MÅ, Lundberg O. Understanding the role of welfare state characteristics for health and inequalities-an analytical review. BMC Public Health. 2013;13:1234.

43. Fritzell S, Ringbäck Weitoft G, Fritzell J, Burström B. From macro to micro: the health of Swedish lone mothers during changing economic and social circumstances. Soc Sci Med. 2007:65:2474-88.

44. Whitehead M, Burström B, Diderichsen F. Social policies and the pathways to inequalities in health: a comparative analysis of lone mothers in Britain and Sweden. Soc Sci Med. 2000;50:255-70.

45. Burström B, Whitehead M, Clayton S, Fritzell S, Vannoni F, Costa G. Health inequalities between lone and couple mothers and policy under different welfare regimes-the example of Italy, Sweden and Britain. Soc Sci Med. 2010;70:912-20
46. Fritzell S, Vannoni F, Whitehead M, Burström B, Costa G, Clayton S, et al. Does non-employment contribute to the health disadvantage among lone mothers in Britain, Italy and Sweden? Synergy effects and the meaning of family policy. Health Place. 2012;18:199-208.

47. Mackenbach JP. The persistence of health inequalities in modern welfare states: the explanation of a paradox. Soc Sci Med. 2012;75:761-9.

48. Reeves A, Basu S, McKee M, Marmot M, Stuckler D. Austere or not? UK coalition government budgets and health inequalities. J R Soc Med. 2013;106:432-6.

49. Kosidou K, Dalman C, Fredlund P, Leea BK, Galanti R, Isacsson G, et al. School performance and the risk of suicide attempts in young adults: a Iongitudinal population-based study. Psychol Med. 2014:44:1235-43.

50. Galanti MR, Hultin H, Dalman C, Engström K, Ferrer-Wreder L, Forsell $Y$, et al. School environment and mental health in early adolescence - a longitudinal study in Sweden (KUPOL). BMC Psychiatry. 2016;16:243.

51. Lager A, Seblova D, Falkstedt D, Lövdén M. Cognitive and emotional outcomes after prolonged education: a quasi-experiment on 320182 Swedish boys. Int J Epidemiol. 2016;46:303-11.

52. Kilian A, Williamson A. What is known about pathways to mental health care for Australian aboriginal young people? A narrative review. Int J Equity Health. 2018;17:12.

53. Zheng $\mathrm{H}$. Do people die from income inequality of a decade ago? Soc Sci Med. 2012;75:36-45.

\section{Ready to submit your research? Choose BMC and benefit from:}

- fast, convenient online submission

- thorough peer review by experienced researchers in your field

- rapid publication on acceptance

- support for research data, including large and complex data types

- gold Open Access which fosters wider collaboration and increased citations

- maximum visibility for your research: over $100 \mathrm{M}$ website views per year

At BMC, research is always in progress.

Learn more biomedcentral.com/submissions 